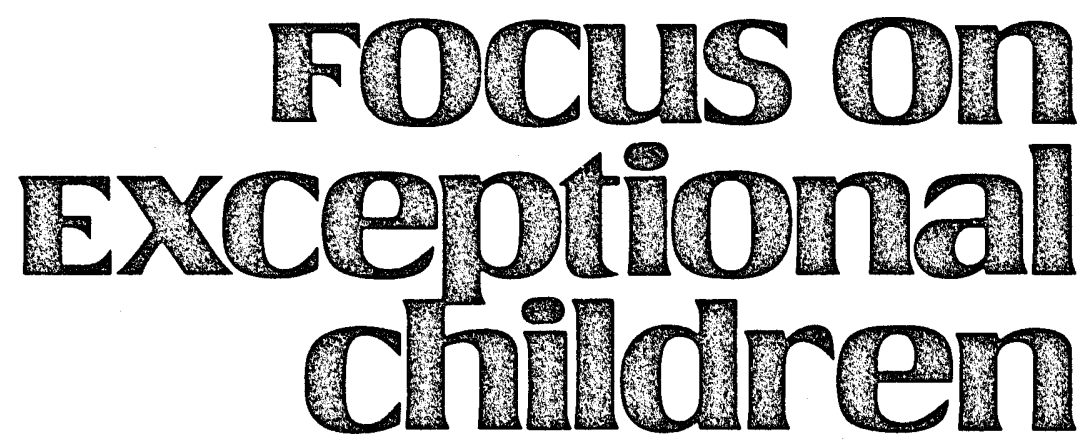

\title{
The Psychosocial Impact of Genetic Disease
}

Audrey Costello

Genetic disease has far-reaching implications for not only the person with the diagnosed condition or the carrier of the genetic trait, but also the family, school, and community in which the affected individual lives. Social and psychological stress can interfere with family functioning. Individuals and their families are confronted with the chronic financial and emotional burden associated with a genetic disease. There may be need for continuous medical care, special education, rehabilitation, or institutionalization. Parents of an affected child or the person with a genetic disorder may feel different from the rest of the community and long to be accepted. To understand the impact of a genetic disease, some features common to most genetic disorders will be reviewed first.

\section{FEATURES OF GENETIC DISEASE}

Schild (1977) identified some features unique to a genetic diagnosis that evoke psychosocial stresses and dilemmas for persons with a genetic disorder and their families. Genetic conditions are permanent, chronic, relate genetically to family members in addition to the affected individual, are complex, evoke labeling, and threaten the lifestyle and well-being of the entire family.

\section{Permanent}

An accurate genetic diagnosis is a lasting reality, irreversible-a fixed attribute of the individual. Its permanency can have a profound effect on how afflicted individuals feel about themselves. When a genetic diagnosis is made, a person's sense of self-adequacy may be threatened or compromised. Genetic conditions that are seriously disabling, debilitating, or stigmatizing may evoke more problems with identity than those that are treatable or readily disguised.

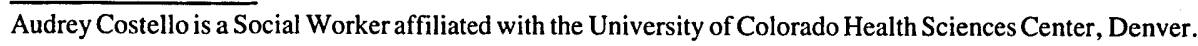




\section{Chronic}

A genetic diagnosis is continuous, ever present. Management of a genetic disease over the course of a lifetime may create chronic strains on the individual and family. Needs such as home aids, special schooling, rehabilitation, and financial pressures may create ongoing stresses for the family. In addition to these realities, the family may experience continual sadness or mourning for the person "who will never be." This concept has been termed "chronic sorrow" (Olshansky, 1962).

Added to these burdens of a chronic nature, a genetic disorder may have a greater impact at certain stages in the developmental life history of affected individuals and their families. Marriage and child-bearing, for example, pose particular threats because they hold concerns about reproductive risks.

\section{Family Association}

Other family members may become involved in the evaluation of a genetic problem or in the assessment of the pattern of inheritance. They may find themselves or their offspring at-risk for a previously unsuspected problem. Depending on

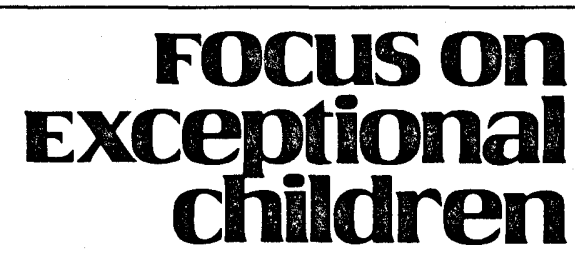

FOCUS ON EXCEPTIONAL CHILDREN (ISSN0015-511X) (USPS 203-360) is published monthly except June, July, and August as a service to teachers, special educators, curriculum specialists, administrators, and those concerned with the special education of exceptional children. This publication is annotated and indexed by the ERIC Clearinghouse on Handicapped and Gifted Children for publication in the monthly Current Index to Journals in Education (CIJE) and the quarterly index, Exceptional Child Education Resources (ECER). It is also available in microform from Xerox University Microfilm, Ann Arbor, MI. Subscription rates: Individuals, \$24 per year; institutions, $\$ 30$ per year. Copyright (C) 1988 , Love Publishing Company. All rights reserved. Reporduction in whole or part without written permission is prohibited. Printed in the United States of America. Second class postage is paid at Denver, Colorado.

POSTMASTER: Send address changes to:

Love Publishing Company

Executive and Editorial Office

1777 South Bellaire Street

Denver, Colorado 80222

Telephone (303) 757-2579

EDITORIAL BOARD

$\begin{gathered}\text { Edward L. Meyen } \\ \text { University of Kansas } \\ \text { Richard J. Whelan } \\ \text { Georgia State University }\end{gathered}$
University of Kansas Medical Center
$\begin{array}{cc}\text { Stanley F. Love } & \text { Carolyn Acheson } \\ \text { Publisher } & \text { Senior Editor }\end{array}$

the diagnosis and the implied risks, established interpersonal relationships within a family may be affected to varying degrees.

\section{Complex}

Many genetic diagnoses involve complicated biological processes that may be beyond the family's level of scientific knowledge and understanding. Therefore, communicating the nature of the disorder or its mode of transmission poses a challenge. Many genetic diagnoses are variable with regard to symptoms and degrees of severity, which may further confuse the facts and increase anxiety.

\section{Labeling}

Like any other diagnostic classification system, genetic diagnosis categorizes and labels. This is helpful in determining etiology, treatment, prognosis, and prevention, but labels also can raise connotations of difference or deviance. Thus, labeling can reinforce biased stereotypes and foster inappropriate fears, responses, and prejudices on the part of others.

\section{Threatening}

A genetic diagnosis has the propensity to precipitate a crisis because of the implied or inherent threats to life functioning or life itself. As a result of the diagnosis or reproductive risks, family plans may have to be altered. If faced with a degenerative disease process or premature death, the affected individual and family may have to alter long-range plans. The lifestyle of the family unit itself may be threatened if the needs of the various family members cannot be met.

\section{THE CRISIS OF DIAGNOSIS}

Diagnosis of a genetic condition may take place at birth, in infancy or childhood, in adolescence, or in adulthood. If the disorder is present at birth, it may interfere with parental attachment. Grief, guilt, and searching for a cause are experienced at all stages. The impact of genetic diagnosis is more intense if the condition is life-threatening or permanently handicapping, interferes with daily routines, or is outwardly observable.

\section{Grief}

When receiving the diagnosis, individuals and their families usually experience intense grief not unlike the grief experienced when a loved person dies. They realize that the person-whether it be their child or themselves-will not be "normal." The affected individual or family may have feelings of shock, disbelief, anger, and depression. In addition to these intense emotions, they may be confused and 
have many questions-often without answers-and uncertainty about the future.

At this time, parents of newborns or children may feel powerless, isolated and alone, or incapable of making decisions. Adolescents and adults who are diagnosed with a genetic disorder experience their own grief reactions in having to come to grips with their new genetic identity while grieving for their "old self."

\section{Guilt}

Parents who are carriers for a genetic trait and who pass on the condition to their offspring may feel responsible for what they have done, even if they were unaware of the trait and had no previous positive family history to alert them to this risk. Adults diagnosed with an autosomal dominant disorder may feel guilty for potentially passing the gene to their offspring.

\section{Searching for Cause}

In addition to the pain and confusion of having a child with a birth defect, parents often are overwhelmed with feelings and fantasies about why it happened. Particularly with diagnoses that are multifactorial, parents frequently ask: What caused this? What are the chances of it happening again? If clear etiological statements cannot be made, parents may blame themselves or each other for real or imagined happenings during pregnancy. They may find their selfesteem at an all time low.

When the diagnosis is made with adolescents or adults, the affected individual also searches for a cause. They may wonder if their behavior or something they did caused them to now have problems. If the disorder is inherited from one or both parents or family "secrets" have been maintained about a genetic disorder, affected adolescents or adults may be resentful and angry toward their parents or extended family.

\section{Bonding}

A genetic diagnosis made prenatally or at birth may interfere with bonding of parents and their infants. In a lifethreatening condition such as trisomy 13 or a congenital heart defect, parents may try not to get too attached for fear they will experience more pain if the infant dies. If the infant survives, their struggle to accept the baby and deal with their feelings of disappointment, guilt, and grief may interfere with their interactions with their baby.

\section{DIFFICULTIES RELATED TO DEVELOPMENTAL STAGES}

A genetic disorder may precipitate increased stress in the affected individual or other family members during specific periods of life. The major developmental stages are infancy, early childhood, school age, adolescence, and adulthood (with its own substages).

\section{Infancy}

During infancy a child needs care, nurturing, and stimulating opportunities to foster growth and development. When the infant has special needs, the additional time required for caretaking may tax the parents. Furthermore, expectations for the child may have to be readjusted. Parents may need help in understanding their child's abilities and accepting their child's abilities and accepting their child's uniqueness. Initial grief, difficulties with attachment, prolonged or repeated hospitalizations, concern over the child's future, and trying to balance the needs of other family members are specific stresses associated with the inflicted child's infancy.

\section{Early Childhood}

In early childhood the two main developmental tasks of any child are (a) to loosen the dependent attachment to mother and (b) to develop a sense of sexual identity (McCollum, 1981). When the child has a genetic disorder, both of these tasks may be more difficult to master. Even when the affected child has normal intellectual and mental functioning, parents may have difficulty allowing the child independence. Discipline problems may result from being over-protective or over-indulgent.

\section{School-Age Years}

At school age an increasing proportion of the child's experience takes place outside the home. His or her association with other children in school, involvement with team sports, church activities, or community organizations, such as Scouts, all contribute to the growing awareness of self, continuing independence from parents, and self-esteem. Peer contacts give children a sense of belonging.

Whether to conceal or disclose information about the child's diagnosis to peers, school personnel, or the affected child himself or herself may be stressful decisions for families. Affected children may become anxious if they sense something "different" about themselves but do not have the necessary information to cope. Parents may fear that their child will be rejected or ridiculed if they share information with peers, school personnel, and others. They frequently want to shield their child from painful encounters. Peers may tease children who look or act different, particularly if they have no information about the reason for the difference.

Giving the child some appropriate information can help to reduce his or her anxiety. It enables the affected child to 
make judgments that gradually help him or her toward independence. This information helps affected children to communicate their needs to teachers, peers, and parents so they do not feel so alone. It gives the child a sense of control and mastery, enabling a more positive self-image.

\section{Adolescence}

Adolescence is a period of rapid physical growth and sexual maturation. As the physical body changes, teenagers have to alter mental images of their physical self. Self-esteem is in a constant state of fluctuation as adolescents alternately like and dislike their changing body. Adolescents who have genetic disorders-particularly with physical manifestations-may have more difficulty as they worry about their physical adequacy and acceptance by peers.

Adolescence is also a time of becoming more independent of parental control. Parents of normal adolescents often have difficulty granting this independence, and when an adolescent has a genetic disorder, stresses may be even greater as parents struggle with recognizing their teenager's capabilities. Adolescents with a genetic diagnosis may feel ambivalent about their own independence-fearful of their future, their ability to provide and care for themselves, and their physical and social activity. If patterns of dependence are fostered, significant problems can ensue.

Fortunately, adolescents who are not intellectually affected have newly developed mental capabilities and are now able to understand biological processes and other complex information. Explaining the diagnosis, anticipating future needs, allowing expression of feelings, encouraging peer relationships, and setting realistic goals can enable acceptance of emotional and physical self and foster independence.

\section{Adulthood}

Adulthood is the time when one achieves independence from the family of origin and forms intimate relationships that may lead to formation of a new family unit. It is a time of establishing oneself in society as a productive and social individual and of developing a sense of identity.

An adult with a genetic condition may have a distorted identity, particularly when disfigurement, loss of body function or body part, or pain is involved. Some persons who have a genetic disease question their capacity to love or be loved. Decisions to date, form intimate relationships, or marry may arouse anxiety in both the affected individual and in potential partners. Low self-esteem may result in avoidance of possible mates, attraction to inappropriate, unavailable, or abusive partners, or sexual promiscuity.

In identifying their capabilities and limitations, genetically affected adults may postpone, delay, or alter career or employment decisions. Architectural barriers may limit career choices, particularly for those who are physically handicapped.

Significant physical or mental handicaps may prohibit adults from gaining complete independence and adequate adult functioning. Despite the limitations imposed by a genetic disorder, however, these adults need continued opportunities for intellectual, psychological, social, and physical development.

\section{Family Changes}

Every family has its own particular style of living. Changes in lifestyle may be necessary because of the needs of the genetically affected individual. The family may have to move closer to medical facilities, rehabilitation programs, or special settings. Leisure-time activities may have to be altered as a result of the drain on time, energy, and finances.

Individual family members may have to change roles and assume new responsibilities. The primary wage earner may seek higher paying employment or take on a second job to cover the additional expenses. If both parents work outside the home, one may have to quit to assume more responsibility for caring for the needs of the affected individual.

Additional changes may occur in the family structure over time. The birth of another child, adult children leaving home, marriage of a family member, and divorce or death of a family member are examples of changes that can precipitate new concerns about the care and management of a family member with a genetic disorder. As parents age, they may become concerned about the affected individual outliving them or worry about who will take their place as caretaker. These concerns may be particularly pervasive if the affected individual is significantly physically or mentally handicapped.

\section{OTHER SOURCES OF PSYCHOSOCIAL STRESS ON THE FAMILY}

\section{Financial Responsibilities}

Care of an individual with a genetic disorder can be very costly. Hospitalization, medical care and supplies, and therapies are all expensive. The family must make decisions about allocation of family resources so that other family member needs are not deprived.

\section{Hospital Experiences}

Many individuals with a genetic disorder require repeated hospitalization and medical services. This sometimes means separation from family members, missed time at school for a child, and absences from work for adults, causing additional stress and demands on the family unit. 
Depending on their developmental level, hospitalized individuals may fear embarrassment, pain, disfigurement, lack of privacy, loss of control, capacity to work or play, loss of sexual function, or death. Hospital experiences may cause the patient to feel helpless. Immobilization and restriction of activities may be emotionally stressful. Parents and spouses of affected individuals must deal with their own fears while simultaneously helping their child or spouse sort out, express, and face their own worries.

\section{Health Services}

Stress sometimes associated with health services relates to inadequate or lack of services or over-servicing in a given geographic area or around a specific diagnosis. Families in rural areas may have difficulty finding a physician who feels comfortable managing a particular diagnosis; large metropolitan areas may have several specialized programs competing for the care and management of a select population.

Parents or the affected individual may think health professionals are interested in them only as "research material." Some may feel abandoned by health professionals; others may be overwhelmed by the multiple health specialists involved in their care. Identifying a primary physician to coordinate care and provide medical information may be necessary to alleviate the stress associated with negotiating the medical systems.

\section{Multiple Community Systems}

Because of the complex needs of some genetically affected individuals, families may utilize the services of a number of agency resources. Frequently more than one agency or system is involved at the same time. Negotiating with and utilizing the services of a variety of systems may put additional stress on family members as they juggle their time and energy to meet the demands of each service. Discrepancies between agencies on how a problem or situation should be handled may arise. Families may need help in sorting out the demands of various agencies and devising a reasonable program without compromising the necessary care.

\section{Placement Decisions}

Significant disabilities in an individual or limited physical resources in a family may lead to considerations for out-ofhome placement. This is a difficult decision, affecting all family members. Thought must be given to every possible alternative, such as home health care, respite care, day care centers, nursing homes, group homes, or institutionalization. Costs, quality of services, and closeness to home must be evaluated before making final decisions. When out-ofhome placement is concluded, feelings of ambivalence, guilt, and inadequacy may arise in the family-and anger, confusion, and loneliness in the individual who is placed.

\section{Reproductive Decisions}

A couple faced with the possibility of an affected child is under tremendous stress. The relationship is tested as the mates make serious and difficult decisions regarding future children. Often, partners disagree on whether to take the chance on a pregnancy. One or the other may feel a need to prove that he or she can produce a normal child, regardless of the risk, or each partner may perceive the extent of the genetic burden differently. A breakdown in communication frequently occurs. Partners may lose interest in sexual activity either because they fear conception or because they feel less than whole.

If they decide to have a child, they must learn to deal with their anxieties during the preganancy. They may seek amniocentesis or other prenatal evaluations, such as ultrasound, for reassurance. The decision to have prenatal evaluation carries its own set of stresses. Although the techniques used for prenatal testing have improved, there continue to be no guarantees that negative results mean that the child will be perfect. Individuals or couples who undergo prenatal testing usually are anxious prior to the procedure and while awaiting results. If the results are positive for a chromosomal or structural abnormality, the partners have to face additional stresses of deciding whether to continue or terminate the pregnancy.

Even though partners may have expressed their feelings about abortion prior to prenatal diagnosis, the decision may still be difficult. Most elective abortions related to genetic indications occur in the second trimester, after the woman has begun feeling fetal movement. Religious, cultural, and ethnic values may take on different meanings when the couple is confronted with an abnormal fetus. Frequently, the threat of an abnormal child is so strong that religious beliefs and personal values become secondary to having a normal, healthy child. To avoid later accusations and guilt, the couple has to reach a joint decision. How to tell family and friends of their decision adds to the stress. Following an elective abortion, the couple may feel a combination of relief, guilt, and grief for the lost fetus.

\section{EVALUATION AND MANAGEMENT}

Some individuals or families are more susceptible to the difficulties related to a genetic diagnosis than are others. Variables that may influence how a person reacts and copes include his or her personality, prior experiences with genetic diagnosis or health problems, particular circumstances related to the disorder, and the meaning each individual attributes to these circumstances. Health personnel's personal problems, interpersonal relationships, ethnic, cultural, and religious background and beliefs, value system, socioeconomic status, and attitudes also may have an impact on how the person reacts. 
For many, the diagnosis of a genetic disorder, the needs or care of the individual with a genetic diagnosis, or the stress of being at-risk for a genetic disorder will precipitate a crisis. Situational events (external events such as birth of a defective child, death, stillbirth), maturational events (when an individual has excessive difficulty in resolving a developmental task), or chronic strain crises (from longterm, daily care and demands of genetic disease) may, at any time during the lifespan of the individual and family, cause upset or disorganization.

Frequently an individual or family comes to the attention of a professional care provider (medical personnel, educators, therapists) during a time of crisis. Regardless of whether the individual or family is in acute crisis, professional care providers should identify vulnerable individuals and families and intervene to prevent the development or exacerbation of psychosocial problems and stresses that may lead to further crisis. To identify the specific needs of the genetic client, each situation must be assessed individually. Areas to identify in assessing individuals and families are:

1. Family information: Data on family size, ages of family members, education, employment, family income, insurance, religion, and ethnic-cultural background

\section{Family functioning}

a. Interpersonal relationships-marital, parent-child, family, significant others

b. Communication skills-with family members, health professionals, and interviewer

c. Health status of family members-physical, emotional, and mental

d. Family stresses-financial, housing, employment, recent change in family constellation or in living situation, school problems, behavior problems, etc.

e. Past and current defenses and coping behaviors

f. Problem-solving skills

g. Decision-making patterns

\section{Social functioning}

a. Utilization of external resources and groups-religious, cultural; extended family group, self-help and support groups, etc.

b. Attitudes toward family roles and responsibilities

c. Attitudes about illness, medical care, health care providers, deviance, abortion

d. Emphasis placed on religious beliefs and value system

e. Social and educational goals for themselves and family members
4. Genetic diagnosis

a. Accuracy of diagnosis

b. Implications for health status and physical or mental functioning

c. Burden of care

d. Affected family members

e. Mode of transmission

f. Risk to other family members

g. Recurrence risks

h. Perceptions of genetic problem

5. Reproductive history
a. Reproductive aspirations
b. Periods of infertility
c. Pregnancy history and outcome-therapeutic abor- tions, miscarriage(s), stillbirth, neonatal death, relin- quishment
d. Previously affected children
e. Birth order and gender of affected children

6. Impressions and assessment

a. Interviewer's impression of individual family members and family unit

b. Family members' assessment of their problem and needs

c. Coping skills and defense mechanisms

d. Worker's assessment of family needs

e. Indicators for high-risk family

f. Indications for referral

Assessment is an ongoing process. At any given time the professional care provider must determine how to respond to what the person is saying about the problem, his or her needs, or any aspect of the situation. The professional's knowledge and understanding of the specific adaptive patterns of a particular individual and family, the stress factors involved in the particular situation, and the specific genetic diagnosis and its manifestations all help the professional find and use internal and external resources for coping with both the reality factors and the emotions that may emerge during the course of treatment.

\section{Coping Mechanisms}

Coping behaviors used in any previous crises may indicate whether the problem was avoided or successfully resolved. Coping mechanisms that previously worked may be employed in the current crises, or the family may need help in exploring alternative coping behaviors. Some positive coping behaviors and activities are (adapted from Johnson, 1979, p. 178):

- Seeks relevant information about the genetic diagnosis.

- Anticipates future problems and actively seeks guidance and answers. 
- Talks about the disease process and rehearses alternative outcomes.

- Plans realistically for the future.

- Learns specific illness-related procedures.

- Sets specific, limited goals that break down overwhelming problems into potentially manageable ones.

- Expresses feelings and recognizes reasons for emotional reaction.

- Requests reassurance and emotional support from family, friends, and medical staff.

- Informs family members, including the affected individual, of genetic diagnosis, prognosis, and risks.

- Participates in support groups and educational programs when appropriate.

- Reviews previous successes in handling difficult situations.

- Recognizes own growth through passage of time.

- Engages in tension-reducing activities (e.g., physical activity, hobbies).

Avoidance behaviors may include:

- Denies or minimizes the seriousness of the crisis (may be directed at the diagnosis itself or at the significance of the diagnosis).

- Does not comply with or refuses treatment.

- Avoids discussion about the genetic disorder.

- Seeks a cure by "doctor-shopping."

- Has unrealistic perceptions of genetic disorders.

- Intellectualizes about the genetic disorder.

- Suppresses, projects, or displaces angry feelings.

- Is unable to accept or adjust to change in the progression of the disease.

- Punishes self through blame or guilt.

- Withdraws from the outside world.

- Is estranged from support system.

- Seeks alternative ways of management (e.g., through religious beliefs or occult healings).

- Makes no change in lifestyle or family roles to meet needs of family members.

- Engages in abusive behaviors to deal with stresses (e.g., drug/alcohol excesses or abuse of family members).

- Makes no provision for positive outlets for own recreation or relaxation.

None of these positive or negative behaviors by itself is sufficient to assess the possible success or failure of crisis resolution. Each behavior must be seen in the context of total assessment of the family unit, individual members, and implications of the crisis situation.

\section{Service Needs}

Even with effective coping skills, the nature and severity of the genetic disorder and its implied threats for the family may create specific service needs. The following services provided by care professionals are adapted from Schild (1977). They include crisis interventions, anticipatory guidance, liaison with health personnel, linkage to support systems, referral to community resources and agencies, case management, family life education, family planning services, supportive counseling, and advocacy.

\section{Crisis Counseling}

Families experiencing a genetic crisis may require help in learning to cope with the disorienting effects of the genetic disorder. They may need support in learning to adjust to their new or changed situation and in developing adaptive coping behaviors.

\section{Anticipatory Guidance/Planning}

Many people with a genetic disorder feel isolated. Encouraging individuals and families to utilize the helping network of family and friends and identifying support systems, such as self-help groups, health programs, and social service agencies, may help them feel less alone.

\section{Liaison with Health Personnel}

Because of the complexity of many genetic disorders, the affected individual may require care from a variety of health professionals. Collaboration in health care services is necessary to most effectively meet the family's needs. With the involvement of multiple health professionals, one of them ideally becomes a liaison between the patient, the family, and the rest of the health care team, to reduce confusion and disruption surrounding management recommendations.

\section{Linkage to Support Systems}

Many people with a genetic disorder feel isolated. Encouraging individuals and families to utilize the helping network of family and friends and identifying support systems, such as self-help groups, health programs, and social service agencies, may help them feel less alone.

\section{Referral to Community Resources and Agencies}

Families with a genetic disorder frequently are overwhelmed with financial, child-care, and management concerns. Referral to appropriate agencies for financial assistance, homemaker services, child care, respite care, and home health care may be necessary for positive family functioning.

\section{Case Management}

Families with a genetic disorder may be receiving services simultaneously from a variety of health, social, educational, 
and rehabilitation agencies. Coordination and management of care through a primary health care provider or fixed point of service may be indicated to avoid duplication of services and to ensure that family needs are met.

\section{Family Life Education}

Genetic patients may have many special needs that cause parents and other family members concern beyond normal questions of discipline and caretaking. Education and assistance relevant to developmental needs, altered behaviors, discipline issues, and roles changes may be indicated to preserve or restore the family's adaptive functioning.

\section{Family Planning Services}

Genetic clients often struggle with reproductive dilemmas. Counseling may prove useful in helping individuals and couples understand all family planning options, deal with emotional responses related to reproductive issues, and make decisions around family planning choices.

\section{Supportive Counseling}

Individuals who are emotionally stressed and overwhelmed by genetic conditions may benefit from supportive counseling. An empathic approach can provide a suitable outlet for emotions, to help the client retain a positive selfimage and reduce tension within the family.

\section{Advocacy}

When the rights of a genetic client are threatened or repealed, the professional care provider may assume an active role as an advocate. He or she might help clients, families, and members of the community to understand and make effective use of health services or take action to bring about needed changes in agency or community services or in organizational and governmental policies and procedures. Whenever possible, clients should be assisted in learning effective strategies for advocating for themselves or collectively with various client groups.

Although individuals or families with, or who are at-risk for, a genetic disorder experience a variety of stresses, they usually are able to cope if they receive adequate information, support, and services. Individuals who seem to be at-risk for psychosocial problems and poor ego functioning may need referral to a social worker or mental health facility for further, in-depth psychosocial evaluation and possible treatment. Psychotherapy should be considered if an individual has preexisting personal problems, problems aggravated by the genetic situation, deficiencies in decision-making processes, extreme and prolonged emotional reactions of guilt, blame, anxiety, depression, or anger, or suicidal or homicidal thoughts.

Referral for marital counseling may be indicated if communication between partners becomes so distorted or dysfunctional that it seriously threatens individual integrity, sexual relations, or the marriage itself. Family counseling may be necessary to deal with the reactions of both affected and non-affected family members, to reinforce positive family relationships, and to restore functioning of the family unit. Group counseling may be effective when members have common social and psychological issues that they are trying to resolve. Knowing others who share similar concerns and challenges can be very supportive.

\section{SUMMARY}

From a psychosocial viewpoint, individuals and families with or at-risk for a genetic disorder face many potential difficulties. Although the stresses and the reactions they evoke are unique to each family or situation, some characteristics, problems, and needs are held in common by most of them. With that common basis, interventions that are individualized for the family and based on assessment of all family members are the most effective in helping them cope with the challenges and crises associated with genetic disorders.

\section{REFERENCES}

Johnson, S.H. (1979). High risk parenting: Nursing assessment and strategies for the family at risk. Philadelphia: J.B. Lippincott.

McCollum, A. (1981). The chronically ill child. New Haven, CT: Yale University Press.

Olshansky, S. (1962). Chronic sorrow: A response to having a mentally retarded child. Social Casework, 43, 190-193.

Schild, S. (1977). Social work with genetic problems. Health \& Social work, 2(1).

\section{ADDITIONAL REFERENCES}

Kumabe, K., Nishida, C., O'Hara, D., \& Woodruff, C. (1977). A handbook for social work education in community health settings. Honolulu: University of Hawaii, School of Social Work.

Schild, S., \& Black, R.B. (1984). Social work and genetics: A guide for practice. New York: Haworth Press.

Weiss, J.O. (1981). Psychosocial stress in genetic disorders: A guide for social workers. Social Work in Health Care, 6(4).

Weiss, J.O., Bernhardt, B., \& Paul, N. (Eds.). (1984). Genetic disorders and birth defects in families and society: Toward interdisciplinary understanding. Birth Defects Original Article Series, 20(4). 